\title{
Randomized Comparison of Helmet CPAP Versus High-Flow Nasal Cannula Oxygen in Pediatric Respiratory Distress
}

\author{
Giovanna Vitaliti MD, Maria Concetta Vitaliti MD, Maria Carla Finocchiaro MD, \\ Vita Antonella Di Stefano MD, Piero Pavone MD, Nassim Matin MD, \\ Nazgol Motamed-Gorji MD, Riccardo Lubrano MD, and Raffaele Falsaperla MD
}

\begin{abstract}
BACKGROUND: The current study aimed to compare the efficacy and safety of 2 noninvasive respiratory support methods, which included helmet CPAP and high-flow nasal cannula (HFNC) in children with respiratory distress admitted to a pediatric intermediate care unit. METHODS: This study was a prospective observational study conducted on children with respiratory distress (age 1-24 months) who were admitted to our acute and emergency operative unit. All included subjects were randomly treated with helmet CPAP or HFNC in a 1:1 fashion until their clinical picture, oxygen saturation, and arterial blood gas (ABG) parameters resolved. The efficiencies of helmet CPAP and HFNC were evaluated by breathing frequency, $\mathrm{S}_{\mathrm{pO}_{2}}, \mathrm{ABG} \mathrm{pH}, \mathrm{ABG} \mathrm{P}_{\mathrm{aCO}}, \mathrm{ABG} \mathrm{P}_{\mathrm{aO}_{2}}$, and $\mathrm{P}_{\mathrm{aO}} / \mathrm{F}_{\mathrm{IO}}$, recorded once at baseline and then after 1 and $6 \mathrm{~h}$ of treatment. Both noninvasive respiratory support modalities were compared with a control group of subjects with respiratory distress under standard therapeutic pharmaceutical protocols. RESULTS: We found that both helmet CPAP and HFNC were efficient in improving the clinical conditions of subjects with mildto-moderate respiratory distress, although clinical response to helmet CPAP was more efficient and rapid compared with HFNC. Children who received respiratory support had a better clinical course in terms of hospitalization, days of intravenous rehydration therapy, and days of drug administration compared with the control group $(P<.001)$. CONCLUSIONS: Based on our knowledge, the present study is the first research comparing the effects of CPAP and HFNC in respiratory distress resolution in a pediatric intermediate care setting. It aims to identify the most efficient treatment to avoid pediatric ICU admissions and endotracheal intubation and reduce the administration of drugs and days of hospitalization. Key words: noninvasive respiratory support; pediatric intermediate care; efficiency; CPAP; HFNC; acute respiratory failure. [Respir Care 2017;62(8):1036-1042. (C 2017 Daedalus Enterprises]
\end{abstract}

\section{Introduction}

Managing a child with respiratory distress is challenging for primary care pediatricians; proper treatment is cru-

Drs Vitaliti, Vitaliti, Pavone, and Falsaperla are affiliated with the Pediatric General and Acute and Emergency Operative Unit, PoliclinicoVittorio Emanuele University Hospital, University of Catania, Catania, Italy. Drs Finocchiaro and Di Stefano are affiliated with the Pediatric General and Acute and Emergency Operative Unit, Cannizzaro Hospital, Catania, Italy. Drs Matin and Motamed-Gorji are affiliated with the School of Medicine, Tehran University of Medical Sciences, Tehran, Iran. Dr Lubrano is affiliated with the Pediatric Nephrology Operative Unit, La Sapienza University of Rome, Italy.

The present study was funded by Nestlé Italia Spa, grant number 1746, performed on October 27, 2016. cial to avoid death, long-term disabilities, and high hospital costs. When respiratory distress is confirmed, its treatment requires adequacy of gas exchange, followed by the diagnosis of the underlying causes and complications. ${ }^{1}$

Among etiological causes of respiratory distress in childhood, bronchiolitis is the most common etiology in infants $<1 \mathrm{y}$ of age admitted to the hospital. ${ }^{1,2}$ Prior studies showed that bronchiolitis represents $17.1 \%$ of all

\footnotetext{
The authors have disclosed no conflicts of interest.

Correspondence: Giovanna Vitaliti MD, AOU Policlinico-OVE, Via Plebiscito n. 628, 95100 Catania, Italy. E-mail: giovitaliti@yahoo.it.
}

DOI: $10.4187 /$ respcare. 05384 
non-elective pediatric ICU admissions, which imposes a heavy resource burden. ${ }^{2}$ Due to this reason, numerous studies have focused on the efficacy of various medications for the management of infants with bronchiolitis, including adrenaline, steroids, salbutamol/albuterol, and hypertonic saline fluids. Nevertheless, none of these studies were successful in showing an improvement of the outcome, a lessening of the burden on health-care systems, or a reduction in the number of pediatric ICU admissions. ${ }^{3}$

The most recent guidelines for management of infants with bronchiolitis and/or other causes of respiratory distress in hospitals emphasize the importance of oxygen therapy, respiratory support, and maintenance of hydration in hypoxia. ${ }^{4}$ Respiratory support has traditionally been the cornerstone of intensive care settings and is usually provided through an escalation of therapies from noninvasive methods to intubation and mechanical ventilation. ${ }^{5-7}$

Among proposed noninvasive respiratory support methods in children with bronchiolitis and/or other etiologic causes, some previous studies have investigated the efficacy of highflow nasal cannula (HFNC) administration, ${ }^{2}$ whereas other studies have used CPAP, due to its ability to increase functional residual capacity with a reduction of apneic episodes. ${ }^{8-10}$

Although there is a sufficient amount of data in the literature on noninvasive respiratory support in the pediatric ICU, its use in pediatric intermediate care units has not been investigated properly. The aim of the present study was to evaluate the efficacy and safety of 2 noninvasive methods of respiratory support in subjects with pediatric respiratory distress admitted to the pediatric acute and emergency room: helmet CPAP and HFNC.

\section{Methods}

The present study was a prospective interventional study in pediatric patients admitted to the emergency department due to respiratory distress. All children with respiratory failure from the emergency room are admitted to the intermediate care area. This zone has been dedicated for those patients who need a monitored setting more intensive than ordinary recovery but not so invasive as to justify their admission to pediatric ICU. This area includes a professional nurse dedicated for the care of a maximum of 4 patients and is furnished with technical and instrumental equipment only for critical patients. This area is welldefined and follows the criteria published by Zimmerman et al. ${ }^{9}$ After admission to the emergency department, critical patients are admitted to our pediatric intermediate care unit, undergoing an initial treatment, and according to Zimmerman's criteria, those patients who do not improve their clinical condition and blood gas analysis parameters after $1 \mathrm{~h}$ of noninvasive support are then admitted to our general pediatric ward or pediatric ICU. Our subjects were selected from 2 health-care services (the Pediatric Acute and

\section{QUICK LOOK}

\section{Current knowledge}

The most recent guidelines for management of infants with bronchiolitis and/or other causes of respiratory distress in hospitals emphasize the importance of oxygen therapy, respiratory support, and maintenance of hydration in hypoxia. Respiratory support has traditionally been the cornerstone of intensive care, and it is usually provided through an escalation of therapies from noninvasive methods to intubation and mechanical ventilation.

\section{What this paper contributes to our knowledge}

The current study is the first research comparing the effects of CPAP and high-flow nasal cannula (HFNC) in respiratory distress resolution in a pediatric intermediate care setting. Both helmet CPAP and HFNC methods were efficient in improving the clinical conditions of subjects with mild-to-moderate respiratory distress, although clinical response to helmet CPAP was more efficient and rapid compared with HFNC.

Emergency Operative Unit, Policlinico-Vittorio Emanuele University Hospital, University of Catania, Italy and the Pediatric Acute and Emergency Operative Unit, Cannizzaro Hospital, Catania, Italy), from November 2014 to December 2015.

We included children with respiratory distress between 1 and 24 months of age, with hemodynamically stable hypoxemia. Patients $<1$ or $>24$ months of age, those with signs and/or symptoms of central apnea and/or chronic respiratory failure, those with cyanogen heart disease, and patients with hemodynamically unstable hypoxemia requiring invasive ventilation were excluded from the study.

The severity of initial presentation and any respiratory distress was assessed at admission by recording clinical signs and symptoms, heart rate and breathing frequency, $\mathrm{S}_{\mathrm{pO}_{2}}$, and arterial blood gas (ABG). All included subjects were randomly treated with helmet CPAP or HFNC in a 1:1 fashion until their clinical condition, oxygen saturation, and $\mathrm{ABG}$ parameters improved. The randomization process was performed by our central computer program, in which all data were appropriately recorded. Blinding was not possible because the interfaces make it obvious. All subjects underwent routine blood tests at admission, and those with signs of bacterial infection received broad-spectrum antibiotic therapy according to the guidelines suggested by Esposito et al. ${ }^{8}$

Helmet CPAP (CPAP: Dimar SRL [Mirandola, Italy] and Age Medical; helmet: StarMed Ventukit, Intersurgical, Mirandola, Italy) was applied for a mean duration of $9.7 \pm 7.82 \mathrm{~h}$ while maintaining a CPAP of $4-7 \mathrm{~cm} \mathrm{H}_{2} \mathrm{O}$, air flow of $30 \mathrm{~L} / \mathrm{min}$, and $\mathrm{F}_{\mathrm{IO}_{2}}$ of $21 \%$. 


\section{Helmet CPAP vs HFNC OXYGEN IN CHILDREN}

Table 1. Demographic Data of Included Subjects

\begin{tabular}{lccccc}
\hline \hline Subject Group & $\begin{array}{c}\text { Age } \\
(\text { mean } \pm \text { SD mo) }\end{array}$ & $\begin{array}{c}\text { Sex } \\
\text { (Female/Male) }\end{array}$ & $\begin{array}{c}\text { Weight } \\
(\text { mean } \pm \text { SD kg) }\end{array}$ & Diagnosis at Admission & $\begin{array}{c}\text { Duration of Treatment } \\
(\text { mean } \pm \text { SD h) }\end{array}$ \\
\hline Helmet CPAP & $5.20 \pm 3.3$ & $12 / 8$ & $5.20 \pm 1.08$ & Bronchiolitis $(n=16)$; pneumonia $(n=4)$ & $9.7 \pm 7.82$ \\
HFNC & $21.5 \pm 2.6$ & $8 / 12$ & $13.9 \pm 2.07$ & $\begin{array}{c}\text { Bronchiolitis }(n=15) ; \text { pneumonia }(n=3) ; \\
\text { acute asthma }(n=2)\end{array}$ & $72.5 \pm 12.52$ \\
Control group & $8.33 \pm 2.4$ & $10 / 9$ & $8.25 \pm 2.15$ & Bronchiolitis $(n=15)$; pneumonia $(n=4)$ & $357.6 \pm 38.4$
\end{tabular}

HFNC $=$ high-flow nasal cannula

High-flow humidified air and oxygen was administered by nasal cannula (Airvo 2, Fisher \& Paykel Healthcare, Auckland, New Zealand) at flows of $1-3 \mathrm{~L} / \mathrm{kg} / \mathrm{min}$ with $\mathrm{F}_{\mathrm{IO}_{2}}$ sufficient to maintain $\mathrm{S}_{\mathrm{pO}_{2}}$ between 96 and $98 \%$. These parameters were determined according to the international guidelines for HFNC in children. ${ }^{11}$

To evaluate the efficiency of helmet CPAP and HFNC support in children with respiratory distress, the following parameters were considered (recorded once at baseline and then 1 and $6 \mathrm{~h}$ after the onset of treatment): frequency, $\mathrm{S}_{\mathrm{pO}_{2}}, \mathrm{ABG} \mathrm{pH}, \mathrm{ABG} \mathrm{P}_{\mathrm{aCO}}, \mathrm{ABG} \mathrm{P}_{\mathrm{aO}_{2}}$, and $\mathrm{P}_{\mathrm{aO}_{2}} / \mathrm{F}_{\mathrm{IO}_{2}}$. Furthermore, both treatment groups were compared with a control group of subjects with respiratory distress (who did not receive any respiratory support) in terms of total days of admission and supporting pharmacologic treatment during hospitalization. After initial treatment in the pediatric intermediate care setting, all subjects were then hospitalized and monitored in a general pediatric operative unit.

This study was approved by the local ethical committee of the University of Catania, Italy. Informed consent was obtained from subjects' parents. Before data publication, parents signed consent for anonymous publication of the data as well.

\section{Statistical Analysis}

Data analysis was performed by standard statistical software. All results were expressed as mean \pm SD values. Power calculation was determined with a free and open source online calculator (http://www.powerandsamplesize.com, Accessed March 22, 2017). Comparison within groups was made using a Student $t$ test for paired groups because differences between values were normally distributed. $P=.043$ was considered to be statistically significant. Three-way analysis of variance was used to compare the efficiency of respiratory support in helmet CPAP subjects, HFNC subjects, and the matched control group in terms of duration of hospitalization and administered pharmacologic therapy.

\section{Results}

The current study included 60 subjects. Forty subjects with mild-to-moderate respiratory distress, of whom 20
Table 2. Clinical and Arterial Blood Gas Parameters Before and After Treatment With Helmet CPAP

\begin{tabular}{llccc}
\hline \hline Studied Parameters & $\begin{array}{c}\text { At Baseline } \\
\text { (mean } \pm \mathrm{SD} \text { ) }\end{array}$ & $\begin{array}{c}\text { After 1 } \mathrm{h} \\
\text { of Treatment } \\
\text { (mean } \pm \mathrm{SD} \text { ) }\end{array}$ & $\begin{array}{c}\text { After 6h } \\
\text { of Treatment } \\
\text { (mean } \pm \mathrm{SD})\end{array}$ & $P$ \\
\hline $\mathrm{S}_{\mathrm{pO}_{2}}, \%$ & $92.9 \pm 1.37$ & $96.9 \pm 1.85$ & $97.8 \pm 1.75$ & .80 \\
$\mathrm{P}_{\mathrm{aO}}, \mathrm{mm} \mathrm{Hg}$ & $40.5 \pm 9.7$ & $56.2 \pm 9.07$ & $56.4 \pm 8.07$ & .40 \\
$\mathrm{P}_{\mathrm{aCO}}, \mathrm{mm} \mathrm{Hg}$ & $60.8 \pm 12.76$ & $45.7 \pm 3.88$ & $43.6 \pm 3.68$ & $<.001$ \\
$\mathrm{pH}$ & $7.31 \pm 0.08$ & $7.40 \pm 0.03$ & $7.39 \pm 0.02$ & .043 \\
$\begin{array}{l}\mathrm{Breathing} \mathrm{frequency,} \\
\text { breaths/min }\end{array}$ & $61.5 \pm 7.26$ & $47.2 \pm 7.22$ & $46.2 \pm 6.72$ & .49 \\
$\mathrm{P}_{\mathrm{aO}} / \mathrm{F}_{\mathrm{IO}_{2}}$ & $158.5 \pm 45.04$ & $260.5 \pm 54.55$ & $261.6 \pm 53.65$ & $<.001$ \\
\hline
\end{tabular}

Table 3. Clinical and Arterial Blood Gas Parameters Before and After Treatment With High-Flow Oxygen by Nasal Cannula

\begin{tabular}{lrrrr}
\hline \hline Studied Parameters & $\begin{array}{c}\text { At Baseline } \\
\text { (mean } \pm \mathrm{SD})\end{array}$ & $\begin{array}{c}\text { After } 1 \mathrm{~h} \\
\text { of Treatment } \\
\text { (mean } \pm \mathrm{SD})\end{array}$ & $\begin{array}{c}\text { After } 6 \mathrm{~h} \\
\text { of Treatment } \\
(\text { mean } \pm \mathrm{SD})\end{array}$ & $P$ \\
\hline $\mathrm{S}_{\mathrm{pO}_{2}}, \%$ & $90.61 \pm 1.34$ & $97.21 \pm 0.53$ & $97.32 \pm 1.23$ & .009 \\
$\mathrm{P}_{\mathrm{aO}_{2}}, \mathrm{~mm} \mathrm{Hg}$ & $43.26 \pm 1.85$ & $63.68 \pm 1.82$ & $61.48 \pm 1.63$ & .009 \\
$\mathrm{P}_{\mathrm{aCO}_{2}}, \mathrm{~mm} \mathrm{Hg}$ & $44.82 \pm 6.44$ & $36 \pm 2.44$ & $36.45 \pm 2.54$ & .90 \\
$\mathrm{pH}$ & $7.31 \pm 0.01$ & $7.35 \pm 0.01$ & $7.37 \pm 0.08$ & .50 \\
$\mathrm{Breathing} \mathrm{frequency,}_{\text {breaths/min }}$ & $54.57 \pm 6.95$ & $38.26 \pm 2.60$ & $34.25 \pm 2.47$ & $>.99$ \\
$\mathrm{P}_{\mathrm{aO}_{2}} / \mathrm{F}_{\mathrm{IO}_{2}}$ & $213.84 \pm 28.23$ & $302.89 \pm 8.58$ & $305.78 \pm 7.46$ & .009 \\
\hline
\end{tabular}

(12 females and 8 males) were treated with helmet CPAP, 20 (8 females and 12 males) were treated with HFNC, and 20 subjects in the control group. Demographic data of the included subjects are shown in Table 1. Subjects' diagnoses included bronchiolitis in 31 cases $(77.5 \%)$, pneumonia in 7 cases $(17.5 \%)$, and acute asthma in 2 cases (5\%).

After $1 \mathrm{~h}$ of treatment, helmet CPAP subjects showed a statistically significant improvement of ABG $\mathrm{pH}(P=.043)$, ABG $\mathrm{P}_{\mathrm{aCO}_{2}}(P<.001)$, and $\mathrm{P}_{\mathrm{aO}_{2}} / \mathrm{F}_{\mathrm{IO}_{2}}(P<.001)$ (Table 2$)$, whereas subjects treated with HFNC demonstrated a statistically significant improvement of $\mathrm{S}_{\mathrm{pO}_{2}} \%(P=.009), \mathrm{P}_{\mathrm{aO}_{2}}$ $(P=.009)$ and $\mathrm{P}_{\mathrm{aO}_{2}} / \mathrm{F}_{\mathrm{IO}_{2}}(P=.009)$ (Table 3$)$. These results remained stable after $6 \mathrm{~h}$ of treatment.

After initial treatment, all subjects were hospitalized and monitored in a general pediatric operative unit. Efficiencies of both noninvasive support methods were com- 


\section{Helmet CPAP vs HFNC OXYGEN IN CHILDREN}

Table 4. Comparison of Subjects Receiving Noninvasive Support With a Control Group in Terms of Length of Hospital Admission and Medication Use

\begin{tabular}{lcrr}
\hline \hline \multicolumn{1}{c}{ Indexes of Efficiency } & $\begin{array}{c}\text { Subjects Receiving } \\
\text { Helmet CPAP }(n=20)\end{array}$ & $\begin{array}{c}\text { Subjects Receiving } \\
\text { HFNC Oxygen }(n=20)\end{array}$ & $\begin{array}{c}\text { Control Group } \\
(n=20)\end{array}$ \\
\hline Duration of hospitalization, mean \pm SD d & $4.9 \pm 1.1$ & $13.1 \pm 1.32$ & $14.91 \pm 1.67$ \\
Use of steroids at standard doses, mean \pm SD d & $3.2 \pm 0.42$ & $7.02 \pm 0.42$ & $8.33 \pm 1.15$ \\
Use of salbutamol at standard doses, mean \pm SD d & $3.2 \pm 0.42$ & $7.02 \pm 0.42$ & $<.001$ \\
Use of antibiotics at standard doses, mean \pm SD d & $1.2 \pm 1.54$ & $4.5 \pm 1.22$ & $7.91 \pm 0.79$ \\
Intravenous rehydration, mean \pm SD d & $4.9 \pm 1.1$ & $5.52 \pm 1.54$ & $4.5 \pm 0.52$ \\
\end{tabular}

HFNC $=$ high-flow nasal cannula

pared regarding noninvasive duration before clinical and $\mathrm{ABG}$ improvement and total days of hospitalization. Findings suggested a more rapid clinical response to helmet CPAP than HFNC with fewer days of hospitalization in the first group of subjects (Table 4). Furthermore, one of the HFNC-treated subjects was admitted to the pediatric ICU due to HFNC failure, with subsequent requirement of endotracheal intubation and invasive ventilation. No case of failure was reported in subjects treated with helmet CPAP.

Finally, children with respiratory distress treated with helmet CPAP and HFNC were compared with a matched randomized control group of 20 children with respiratory distress (whose demographic data are shown in Table 1) which were treated with standard pharmaceutical protocols only. Current findings suggested that ventilated subjects had a better clinical course in terms of hospitalization; days of intravenous rehydration therapy; and days of administration of (systemic and/or inhaled) steroids, inhaled salbutamol, and systemic antibiotics $(P<.001)$ (see Table 4$)$.

\section{Discussion}

This study showed that both helmet CPAP and HFNC methods were efficient in improving the clinical conditions of subjects with mild-to-moderate respiratory distress when compared with a control group, although clinical response to helmet CPAP was more efficient and rapid compared with that of HFNC-treated children. Moreover, whereas helmet CPAP was responsible for a statistically significant improvement of $\mathrm{pH}, \mathrm{ABG} \mathrm{P}_{\mathrm{aCO}_{2}}$, and $\mathrm{P}_{\mathrm{aO}} / \mathrm{F}_{\mathrm{IO}_{2}}$, $\mathrm{HFNC}$ was more effective in improving $\mathrm{S}_{\mathrm{pO}_{2}} \%, \mathrm{ABG}_{\mathrm{aO}_{2}}$, and $\mathrm{P}_{\mathrm{aO}} / \mathrm{F}_{\mathrm{IO}_{2}}$.

HFNC therapy delivers a high flow and heated humidified oxygen into the nasal passages. Humidified delivery prevents mucous plugging and improves comfort. ${ }^{12}$ In detail, HFNC exceeds the peak inspiratory flow so that a precise $\mathrm{F}_{\mathrm{IO}_{2}}$ can be delivered without dilution of the administered oxygen through entrainment of room air into the nasal passages during inspiration. By exceeding peak inspiratory flow, HFNC therapy provides some of the driv- ing pressure in the upper airway during inspiration, thereby reducing the work that the patient is required to perform. The flow during expiration washes out the dead space of the upper airway, reducing the ventilatory requirement for the patient. The expiratory resistance provides some PEEP, thereby increasing functional residual capacity and oxygenation, and the small amount of PEEP delays small airway closure during expiration, improving tidal ventilation. Nevertheless, the flow must be humidified for nasal comfort, and this humidification might improve mucus clearance and prevent mucous plugging; however, this is a minor benefit compared with the other physiologic benefits.

However, the clinical efficacy of HFNC as a therapeutic approach to bronchiolitis has only been reported in nonexperimental observational studies, which indicates lack of appropriately powered randomized studies with welldefined clinically important outcomes..$^{13,14}$ Some clinical studies using HFNC in a non-randomized design have shown a reduction in intubation rates in critically ill infants in intensive care settings. ${ }^{15-17}$ Pilot studies have also investigated the use of HFNC in general pediatric ward settings, suggesting that this method is safe and efficient. ${ }^{18}$ Their results indicate that pediatric ICU admission rates could be significantly reduced by 2.5 times compared with a control group. ${ }^{18}$ Franklin et al have proposed an extensive prospective randomized, controlled trial on the use of HFNC in children with bronchiolitis to assess the efficiency of this method in resolving respiratory distress and avoiding admission to the pediatric ICU. ${ }^{2}$

The current study highlights the efficiency of HFNC in improving clinical conditions and blood gas exchanges of children affected by bronchiolitis. This treatment revealed a statistically significant improvement of $\mathrm{S}_{\mathrm{PO}_{2}} \%(P=.009)$, ABG $\mathrm{P}_{\mathrm{aO}_{2}}(P=.009)$, and $\mathrm{P}_{\mathrm{aO}_{2}} / \mathrm{F}_{\mathrm{IO}_{2}}(P=.009)$ when compared with parameters recorded at baseline (see Table 3 ), which are consistent with the mechanism of action of HFNC. Nevertheless, HFNC failed in one subject, who required endotracheal ventilation due to gradual deterioration of clinical conditions and lack of response to noninvasive support after the first $24 \mathrm{~h}$. Future studies should 
clarify risk factors for eventual HFNC failure in pediatric patients with respiratory distress.

Our study showed a more efficient response in helmet CPAP-treated subjects compared with the HFNC group. During CPAP administration, the patient's airway is maintained throughout the respiratory cycle at a selected constant pressure (CPAP), which is higher than the atmospheric pressure. This method is used to improve respiratory mechanics and gas exchange in patients with intact neuromuscular function, representing a supportive therapy in patients with various forms of respiratory distress. CPAP acts through improving arterial oxygenation and respiratory mechanics and reducing the patient's respiratory drive and effort. ${ }^{19-21}$ Because the inspiratory effort creates a negative pressure inside the thorax, the ventricle afterload is decreased. Accordingly, a decrease in inspiratory effort implies a reduction in the left ventricle afterload. Therefore, venous return and ventricle sizes are decreased with a parallel drop in the wall tension and myocardial oxygen consumption. ${ }^{19-21}$ In patients with non-hydrostatic pulmonary edema, CPAP could improve gas exchange and respiratory mechanics, thereby increasing the end-expiratory lung volume and preventing alveolar collapse..$^{19-21}$ The alveolar extension provides a greater gas exchange surface, which improves the respiratory mechanics of ventilation and results in a consequent decrease of $\mathrm{P}_{\mathrm{aCO}_{2}}$ in blood gas analysis. ${ }^{19-21}$ Moreover, CPAP has been demonstrated to be efficient in subjects with respiratory distress associated with neurological conditions, such as autoimmune encephalitis. ${ }^{22}$

In the current study, CPAP was delivered by helmet, since the lack of pressure points on the face helps to avoid skin necrosis and pain. It also reduces discomfort and improves the patient's tolerance. Similar to HFNC, helmet CPAP was found to be efficient in improving respiratory distress after the first few hours of treatment, and its influence was proved to be more effective on $\mathrm{ABG} \mathrm{pH}$ $(P=.043), \mathrm{ABGP}_{\mathrm{aCO}_{2}}(P<.001)$, and $\mathrm{P}_{\mathrm{aO}_{2}} / \mathrm{F}_{\mathrm{IO}_{2}}(P<.001)$ changes (see Table 2 ). None of the subjects treated with CPAP required transfer to the pediatric ICU in this study. Compared with HFNC, helmet CPAP showed a higher efficiency in resolving respiratory distress (see Table 4). This was mostly due to the effect of CPAP on alveolar extension, which causes an increase of the alveolar surface responsible for blood gas exchange. Nevertheless, we have to consider that our CPAP group was younger than the HFNC subjects, and contained more females and fewer asthma causes. Their blood gases at baseline were also wildly different, although we have to consider that younger age is a risk factor for respiratory instability, respiratory distress worsening, and treatment failure. On the other hand, the amount of extrathoracic dead space is different in different-sized children. If one of the theories for HFNC "improving" ventilation is dead space washout, then smaller children would be more likely to benefit, but also larger children with higher flows can benefit from this method of respiratory support. This assumption highlights the need for further stratification studies on the efficiency of HFNC and CPAP in different age groups.

The efficiency of CPAP in pediatric respiratory distress has been investigated since 1981, when Beasley and Jones ${ }^{23}$ retrospectively described 23 children with bronchiolitis, showing a positive outcome after treatment with CPAP. Nevertheless, few data have since been published in this regard, and the experiences on pediatric wards outside of neonatal ICU and pediatric ICU settings are scarce. To our knowledge, the first study on the use of noninvasive respiratory support in a non-intensive care setting was published in 2005 by Prado et al, ${ }^{24}$ who prospectively evaluated the medical records of 14 subjects (between 1 month and $13 \mathrm{y}$ of age). In that study, the presence of pulmonary restrictive diseases ( $80 \%$ of cases) was found to be the main indication for bi-level positive airway pressure. In the other cases, NIV was performed in subjects who used NIV at home and had exacerbations of their neuromuscular respiratory disease plus subjects with hypoxic and hypercapnic respiratory distress. ${ }^{24}$ In this study, only one subject required intubation for mechanical ventilation, while all the other subjects improved.

In 2008, Thia et a ${ }^{25}$ published a randomized controlled trial investigating the use of nasal CPAP in bronchiolitis in a pediatric intermediate care setting, which included 29 children treated randomly by CPAP or standard treatment. The authors found that CPAP significantly decreased $\mathrm{P}_{\mathrm{aCO}}$ levels compared with standard treatment. Moreover, CPAP demonstrated a significantly stronger reduction in $\mathrm{P}_{\mathrm{aCO}}$ when it was used at first, compared with when it was used afterward. CPAP was well-tolerated, and no complications were detected.

A systematic review of Jat and Mathew ${ }^{26}$ included 2 studies of 50 subjects $<12$ months of age. In one study, the authors found a high risk of bias for incomplete outcome data and selective reporting, whereas both studies had an unclear risk of bias for several domains, including random sequence generation. The effect of CPAP in children with acute bronchiolitis was found indeterminate due to imprecision around the effect estimate. One trial found that CPAP significantly improved breathing frequency compared with no CPAP application, whereas the other study reported no difference between groups with no numerical data to pool. Changes in arterial oxygen saturation were measured in only one trial, and the results were imprecise. The effect of CPAP on the change in $\mathrm{P}_{\mathrm{aCO}_{2}}$ was also imprecise. Change in $\mathrm{P}_{\mathrm{aO}}$, hospital admission rate (from emergency department to hospital), duration of emergency department stay, requirement for ICU admission, local nasal effects, and shock were not assessed in either study. Therefore, it was concluded that the effect of CPAP 
in children with acute bronchiolitis is uncertain due to limited evidence available, which underscores the need for further studies and more extensive trials. ${ }^{27}$

Reviewing the literature on the 2 aforementioned noninvasive support modalities, very few studies that compare the efficacy of CPAP versus HFNC in resolving respiratory distress and avoiding pediatric ICU admissions have been published. In fact, there is conflicting evidence about the ability of HFNC devices to produce clinically important PEEP, since some research studies have demonstrated that HFNC levels of PEEP are too low to be clinically important. $27-30$

One retrospective case review compared 2 methods of noninvasive support in 34 infants with bronchiolitis admitted to pediatric ICU during bronchiolitis seasons of 2 consecutive years. ${ }^{30}$ Infants admitted during the first year received CPAP, whereas those in the subsequent year received HFNC with oxygen flow of up to $3 \mathrm{~L} / \mathrm{kg} / \mathrm{min}$ (up to a maximum of $8 \mathrm{~L} / \mathrm{min}$ ). The authors described a significant mean maximum breathing frequency in $\mathrm{F}_{\mathrm{IO}_{2}}$ and a significant increase in the noninvasive respiratory support, but they found no differences between the 2 groups for both of these parameters. ${ }^{31}$ To our knowledge, this is the only study comparing the efficiency of HFNC and CPAP in children with respiratory distress. Since the aforementioned study was performed in a pediatric ICU setting, we can confirm that the current study is the first ever performed on CPAP versus HFNC efficiency in a pediatric intermediate care setting.

Previous literature has already underscored the need to perform further clinical studies to evaluate the effect of CPAP and HFNC on important clinical outcomes and with various levels of care. ${ }^{32,33} \mathrm{In}$ the current study, we found a decrease of pediatric ICU admission of $97.5 \%$ (only one HFNC-treated case required endotracheal intubation in the pediatric ICU). Helmet CPAP was found to be more efficient than HFNC in resolving respiratory distress. This correlation was observed regarding duration of treatment (from admission to evidence of clinical and ABG improvement) and duration of hospitalization and pharmaceutical drug administration (see Tables 1 and 4). Moreover, it was found that supported subjects had a better clinical course compared with the control group (20 children affected by mild-to-moderate respiratory distress for bronchiolitis), since their total length of hospital stay and pharmaceutical drug consumption were statistically and significantly lower than the control group (see Table 4). It should be noted that routine blood analyses were carried out for all of the children at admission, and for those with signs of bacterial infections, broad-spectrum antibiotic therapy was started at the onset of hospitalization. There was no septic shock reported.

We should mention that our study also presents some weaknesses, such as treatment allocation that was not blinded and the choice for heterogeneous disease groups, due to the heterogeneity of the population admitted to our complex O.U. during the study period. Moreover, the different age and size of the 2 studied groups may represent an important influence on the final results, as far as blood gas differences at admission between the studied groups, before any treatment was performed. Therefore, this may encourage further study with a larger sample size and a more uniform distribution of demographic parameters of the included subjects.

The significance of the current findings is due to vast economic burden of bronchiolitis in children, since the economic burden of infants hospitalized with bronchiolitis is estimated to be 1.73 billion United States dollars/y. In Australia, approximately 11,000 infants with bronchiolitis require hospital admission per year. In 2013, 1,254 of these 11,000 cases $(12 \%)$ were admitted to a pediatric ICU.5,34 Therefore, it is crucial to establish new protocols for the treatment of respiratory distress in pediatric emergency departments to avoid high rates of pediatric ICU admissions.

\section{Conclusions}

To our knowledge, the current study is the first paper comparing the effects of CPAP and HFNC in respiratory distress resolution in a pediatric intermediate care setting. The significance of this study is due to the economic burden of respiratory distress in pediatric patients; therefore, it aims to identify the most efficient method of treatment to avoid pediatric ICU admissions and endotracheal intubation and also to reduce the administration of medications and days of hospitalization.

CPAP and HFNC are conceptually attractive modalities for infants with respiratory distress and bronchiolitis and may improve physiological and clinical outcomes associated with respiratory distress and failure. To date, observational studies have suggested that CPAP and HFNC reduce the need for intensive care, but no evidence from randomized controlled trials has demonstrated this to be the case. High-quality randomized controlled trials using standard methodology should be considered to identify whether HFNC and CPAP confer benefits on important clinical outcomes for infants with bronchiolitis.

\section{ACKNOWLEDGMENTS}

We thank Stacy Taylor for thoroughly revising the manuscript for language and grammar.

\section{REFERENCES}

1. Green TP, Steinhorn DM. The treatment of acute respiratory failure in children: a historical examination of landmark advances. J Pediatr 2001;139(4):604-608.

2. Franklin D, Dalziel S, Schlapbach LJ, Babl FE, Oakley E, Craig SS, et al. Early high flow nasal cannula therapy in bronchiolitis, a pro- 


\section{Helmet CPAP vs HFNC OXYGEN IN CHILDREN}

spective randomised control trial (protocol): a paediatric acute respiratory intervention study (PARIS). BMC Pediatr 2015;15:183.

3. Zorc JJ, Hall CB. Bronchiolitis: recent evidence on diagnosis and management. Pediatrics 2010;125(2):342-349.

4. Oakley E, Borland M, Neutze J, Acworth J, Krieser D, Dalziel S, et al. Nasogastric hydration versus intravenous hydration for infants with bronchiolitis: a randomised trial. Lancet Respir Med 2013;1(2): 113-120.

5. Essouri S, Chevret L, Durand P, Haas V, Fauroux B, Devictor D. Non-invasive positive pressure ventilation: five years of experience in a pediatric intensive care unit. Pediatr Crit Care Med 2006;7(4): 329-334.

6. Javouhey E, Barats A, Richard N, Stamm D, Floret D. Non-invasive ventilation as primary ventilatory support for infants with severe bronchiolitis. Intensive Care Med 2008;34(9):1608-1614.

7. Lazner MR, Basu AP, Klonin H. Non-invasive ventilation for severe bronchiolitis: analysis and evidence. Pediatr Pulmonol 2012;47(9): 909-916.

8. Esposito S, Leone S. [Management of serious bacterial infections: general considerations]. Infez Med 2005;Suppl:3-6.

9. Zimmerman JE, Wagner DP, Knaus WA, Williams JF, Kolakowski D, Draper EA. The use of risk predictions to identify candidates for intermediate care units: implications for intensive care utilization and cost. Chest 1995;108(2):490-499.

10. Chidini G, Piastra M, Marchesi T, De Luca D, Napolitano L, Salvo I, et al. Continuous positive airway pressure with helmet versus mask in infants with bronchiolitis: an RCT. Pediatrics 2015;135(4):e868-e875.

11. Mikalsen IB, Davis P, Øymar K. High flow nasal cannula in children: a literature review. Scand J Trauma Resusc Emerg Med 2016; 24:93.

12. Hough JL, Pham TM, Schibler A. Physiological effect of high flow nasal cannula in infants with bronchiolitis. Pediatr Crit Care Med 2014;15(5):e214-e219.

13. Mayfield S, Bogossian F, O'Malley L, Schibler A. High-flow nasal cannula oxygen therapy for infants with bronchiolitis: pilot study. J Paediatr Child Health 2014;50(5):373-378.

14. Bressan S, Balzani M, Krauss B, Pettenazzo A, Zanconato S, Baraldi E. High-flow nasal cannula oxygen for bronchiolitis in a pediatric ward: a pilot study. Eur J Pediatr 2013;172(12):1649-1656.

15. Keenan SP, Sinuff T, Cook DJ, Hill NS. Does noninvasive positive pressure ventilation improve outcome in acute hypoxemic respiratory failure? A systematic review. Crit Care Med 2004;32(12):2516-2523.

16. Schibler A, Pham TM, Dunster KR, Foster K, Barlow A, Gibbons K, Hough JL. Reduced intubation rates for infants after introduction of high-flow nasal prong oxygen delivery. Intensive Care Med 2011; 37(5):847-852.

17. Kelly GS, Simon HK, Sturm JJ. High-flow nasal cannula use in children with respiratory distress in the emergency department: predicting the need for subsequent intubation. Pediatr Emerg Care 2013; 29(8):888-892.

18. Bellani G, Patroniti N, Greco M, Foti G, Pesenti A. The use of helmets to deliver non-invasive continuous positive airway pressure in hypoxemic acute respiratory failure. Minerva Anestesiol 2008; 74(11):651-656

19. Tonnelier JM, Prat G, Nowak E, Goetghebeur D, Renault A, Boles JM, L'her E. Non-invasive continuous positive airway pressure ven- tilation using a new helmet interface: a case-control prospective pilot study. Intensive Care Med 2003;29(11):2077-2080.

20. Hilbert G, Gruson D, Vargas F, Valentino R, Gbikpi-Benissan G, Dupon $\mathrm{M}$, et al. Non-invasive ventilation in immunosuppressed patients with pulmonary infiltrates, fever, and acute respiratory failure. N Engl J Med 2001;344(7):481-487.

21. Conti G, Marino P, Cogliati A, Dell'Utri D, Lappa A, Rosa G, Gasparetto A. Non-invasive ventilation for the treatment of acute respiratory failure in patients with hematologic malignancies: a pilot study. Intensive Care Med 1998;24(12):1283-1288.

22. Sartori S, Nosadini M, Cesaroni E, Falsaperla R, Capovilla G, Beccaria F, et al. Paediatric anti-N-methyl-D-aspartate receptor encephalitis: the first Italian multicenter case series. Eur J Paediatr Neurol 2015;19(4):453-463.

23. Beasley JM, Jones SE. Continuous positive airway pressure in bronchiolitis. Br Med J 1981;283:1506. doi: 10.1136/bmj.283.6305.1506.

24. Prado F, Godoy MA, Godoy M, Boza ML. Pediatric non-invasive ventilation for acute respiratory failure in an intermediate care unit. Rev Med Chil 2005;133(5):525-533.

25. Thia LP, McKenzie SA, Blyth TP, Minasian CC, Kozlowska WJ, Carr SB. Randomised controlled trial of nasal continuous positive airways pressure (CPAP) in bronchiolitis. Arch Dis Child 2008; 93(1):45-47.

26. Jat KR, Mathew JL. Continuous positive airway pressure (CPAP) for acute bronchiolitis in children. Cochrane Database Syst Rev 2015; (1):CD010473.

27. Lampland AL, Plumm B, Meyers PA, Worwa CT, Mammel MC. Observational study of humidified high-flow nasal cannula compared with nasal continuous positive airway pressure. J Pediatr 2009; 154(2):177-182.

28. Saslow JG, Aghai ZH, Nakhla TA, Hart JJ, Lawrysh R, Stahl GE, Pyon KH. Work of breathing using high-flow nasal cannula in preterm infants. J Perinatol 2006;26(8):476-480.

29. Essouri S, Durand P, Chevret L, Balu L, Devictor D, Fauroux B, Tissières $\mathrm{P}$. Optimal level of nasal continuous positive airway pressure in severe viral bronchiolitis. Intensive Care Med 2011;37(12): 2002-2007.

30. Lavizzari A, Veneroni C, Colnaghi M, Ciuffini F, Zannin E, Fumagalli M, et al. Respiratory mechanics during NCPAP and HFNC at equal distending pressures. Arch Dis Child Fetal Neonatal Ed 2014; 99(4):F315-F320

31. Metge P, Grimaldi C, Hassid S, Thomachot L, Loundou A, Martin C, Michel F. Comparison of a high-flow humidified nasal cannula to nasal continuous positive airway pressure in children with acute bronchiolitis: experience in a pediatric intensive care unit. Eur J Pediatr 2014;173(7):953-958

32. Sinha IP, McBride AKS, Smith R, Fernandes RM. CPAP and highflow nasal cannula oxygen in bronchiolitis. Chest 2015;148(3):810823.

33. Falsaperla R, Elli M, Pavone P, Isotta G, Lubrano R. Noninvasive ventilation for acute respiratory distress in children with central nervous system disorders. Respir Med 2013;107(9):1370-1375.

34. Hasegawa K, Tsugawa Y, Brown DF, Mansbach JM, Camargo CA Jr. Trends in bronchiolitis hospitalizations in the United States, 20002009. Pediatrics 2013;132(1):28-36.

This article is approved for Continuing Respiratory Care Education credit. For information and to obtain your CRCE

(free to AARC members) visit www.rcjournal.com

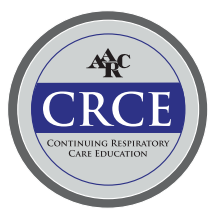

